\title{
UMA HISTÓRIA DA SEXUALIDADE BURGUESA OU A "TESTEMUNHA" QUE NÃO QUERIA VER ${ }^{1}$
}

\section{Sandra Azeredo*}

Publicada na Áustria em 2000, a biografia de Sidonie Csillag, uma mulher centenária, nascida em 1900 em Viena, tendo lá permanecido até 1940, me interessou, sobretudo, por se tratar de uma paciente de Freud, sobre quem ele publicou um estudo de caso em 1920, buscando entender a "origem e desenvolvimento" da homossexualidade em mulheres. ${ }^{2}$ As autoras, Ines Rieder e Diana Voigt, são conterrâneas de Sidonie, nome que, conforme escrevem no prefácio, inventaram para "a personagem" dessa "trama", que é uma "história verdadeira", obtida através da transcrição de várias horas de conversa gravadas e uma extensa documentação. Rieder é escritora e Voigt é psicóloga e, bem no final da trama do livro, elas aparecem como personagens que são as "duas jovens amigas" de Sidonie, a quem ela contava sua história. O prefácio aponta a falta da "vida e a experiência homossexuais" na imensa literatura produzida sobre a Viena do fin de siècle, sugerindo que o livro possa suprir essa falta.

\footnotetext{
* Professora Titular da Faculdade de Filosofia e Ciências Humanas da UFMG.

${ }^{1}$ Resenha do livro REIDER, Ines, VOIGT, Diana. Desejos Secretos: a história C., a paciente homoxessual de Freud. Irad.: Laura Barreto. São Paulo: Companhia das Letras, 2008.

${ }^{2}$ FREUD, Sigmund. The Psychogenesir of a case of homossexuality in a woman. In.: RIEF, P. Sexuality the psychlogy of love. Nova Iorque: Coclice Books, 1963. p. 133-159.
} 
Realmente, no livro, sexo está em toda parte, seja nas estratégias das mulheres - homossexuais ou não (inclusive Sidonie e sua amada Leonie) para arranjarem casamentos - muitas vezes - de fachada de modo a preservarem sua posição econômica, seja nas diversões sexuais das mulheres que, no auge da crueldade, chegavam a usar peixinhos como "dignos antecessores do vibrador moderno" (p. 122). Mas era preciso que fosse uma sexualidade que estivesse "à altura" (expressão muito usada pela personagem Sidonie) de sua classe social. Afinal, os pais de Sidonie buscaram em Freud uma ajuda médica para "trazer a filha de volta à razão e ao caminho da normalidade" (p. 42).

Trata-se, na verdade, de uma história da vida privada contada por uma mulher burguesa, "uma judia que não queria sê-lo, ingênua e politicamente ignorante", chamada de "anti-semita" pelo irmão, a quem esta reafirma "que não gosta de judeus" (p. 175), que desaprova a escolha do marido de uma amiga pelo fato -" o mais importante"- de ele ser judeu (p. 164). As fotos que ilustram o livro são basicamente retratos de pessoas bem vestidas, com chapéus e casacos de pele (há mesmo uma necessidade de sempre se estar mencionando os casacos de peles das "damas" - a "estola de raposa polar", o "casaco de pele de castor", etc.), dentro de casas luxuosas, também ornamentadas com peles de animais. $\mathrm{O}$ foco são os interiores e a perspectiva do livro é uma perspectiva burguesa. O livro de Rieder e Voigt mostra a "sexualidade tagarela" da burguesia, de que nos fala Michel Foucault, em sua História da Sexualidade I" e também a "perversão da sociedade moderna", produto da "interferência de um tipo de poder sobre os corpos e seus prazeres" (1977: 47-48). Pode-se observar nas várias passagens da trama do livro como a burguesia se preocupou em "assumir um corpo e uma sexualidade - de garantir para si a força, a perenidade, a proliferação secular deste corpo pela organização de um dispositivo de sexualidade. E este processo estava ligado ao movimento pelo qual ela afirmava sua diferença e sua hegemonia" (1977, p. 118-119).

${ }^{2}$ História da Sexualidade I A vontade de saber. Trad. M. T. Albuquerque e J. A. G. Albuquerque. Rio: Graal, 1977.

Temáticas, Campinas, 20(40): PG-PG, ago./dez. 2012 
A personagem Sidonie obteve a nacionalidade cubana, na época de Batista, durante a Segunda Guerra, quando teve que fugir de Viena, porém renunciou a essa nacionalidade depois da revolução, pois, para ela, "Fidel Castro e a revolução, que em 1959 fascinaram não apenas a ilha do açúcar, mas o mundo, eram... um horror". Adotou novamente a cidadania austríaca e, mais tarde, "se sentiria feliz por não possuir o passaporte de um Estado comunista" (p. 372). Também "apreciava a estabilidade do regime de Franco", considerando que "um Estado conservador, de preferência monarquista, era o melhor entre todos os sistemas" (p. 380).

Em várias passagens da biografia, a personagem Sidonie se identifica como uma "mulher mimada", como as outras mulheres de sua classe social. Por exemplo, constata "com horror" em certa época de sua vida de casada, que "para administrar e cuidar de seu novo lar precisava se contentar com apenas uma empregada" devido às restrições financeiras do marido (p. 194). A mãe de Sidonie, Emma, é descrita como o protótipo dessa mulher mimada. Era ela que administrava um "lar gigantesco, com onze pessoas ao todo". A impressão da menina Sidi de que o lar se administrava sozinho, e "muito bem", se devia ao trabalho invisível de empregadas/os da casa, que acordavam cedo, preparavam e serviam o café da manhã, trabalhavam o dia inteiro, e só iam para a cama "depois da limpeza dos restos do jantar, da lavagem da louça, de tirar as colchas e arrumar as camas e, sendo necessário, guarnece-las com uma bolsa de água quente" (p. 58), enquanto as damas e cavalheiros (especialmente as primeiras) acordavam tarde, cuidavam da própria aparência, passeavam, seguiam a moda e faziam compras nas ruas chiques da cidade. Há, assim, uma demarcação bem nítida dos espaços da classe trabalhadora e da classe burguesa e também dos espaços de homens e mulheres na classe burguesa, onde o homem trabalha e a mulher não trabalha e gasta o dinheiro do homem: "Sidi sabe que tudo isso [as atividades da mãe] devora enorme somas de dinheiro e admira a paciência e generosidade do pai em relação aos caprichos da mulher" (p. 58-59).

No artigo de Freud sobre sua breve análise de Sidonie, há também essa demarcação de espaços femininos e masculinos. Freud relaciona a 
homossexualidade de Sidonie - seu interesse por mulheres - a algumas características masculinas, inclusive "uma atitude masculina em relação ao objeto" amado, preferindo ser a amante e não a amada (1963, p. 141). No artigo, Freud a descreve como sendo bonita, e embora não houvesse nenhum "desvio óbvio do tipo físico feminino" apresentava "o porte alto de seu pai e suas feições eram duras e não meigas como as de uma menina" (1963, p. 140). Já que, na biografia, Sidonie descreve o pai como "baixinho e gorducho", podemos entender que "o porte alto" de que fala Freud esteja se referindo mais à função paterna, a uma qualidade intrínseca dos homens da burguesia - potenciais pais de família e provedores, independentemente de sua figura física. Escrevendo em 1920, Freud fala sobre um forte "complexo de masculinidade" em Sidonie, sobre o desenvolvimento de uma "inveja do pênis pronunciada" ao "inspecionar" os órgãos genitais do irmão mais novo e sobre uma "forte fixação à mãe" (1963, p. 156).

Rieder e Voigt escrevem que em seus encontros com Leonie quando saía das sessões de análise com Freud, Sidonie se enfurecia e debochava das interpretações dele e, no final de sua vida, ao falar de Leonie com as autoras, como sempre fazia, revivendo como tomava sua mão nas suas e a beijava, se lembra de Freud com "cólera e desprezo": "ainda hoje se alegra com sarcasmo ao pensar que, em seu caso, sua lábia e seu esforço tinham sido inúteis. Era um imbecil. E ponto final" (p. 415).

Pode-se ver ao longo da trama do livro como, a partir da sexualidade que se tinha empenhado em constituir, a burguesia apresentava, como escreve Foucault, "um corpo 'de classe', com uma saúde, uma higiene, uma descendência, uma raça”" (1977, p. 117). E como a psicanálise, reforçando o papel diferenciador de classe, veio acolher aquelas e aqueles que podiam recorrer a ela para tratar os efeitos patogênicos da repressão da sexualidade (1977, p. 121). Essa repressão, no entanto, não significava simplesmente a imposição da norma heterossexual, mas, pelo contrário, observa-se no livro a "multiplicidade de elementos discursivos que podem entrar em estratégias diferentes", de que fala Foucault (1977, p. 95), a serviço de um dispositivo da sexualidade que pertence "a uma tecnologia complexa" (1977, p. 120). 
Na minha leitura, portanto, o livro de Rieder e Voigt não trata simplesmente da vida e experiência homossexuais, mas compõe um retrato da vida privada da burguesia e as estratégias de manutenção de seus privilégios, através do relato de uma mulher que, como escrevem as autoras, "não será testemunha das manifestações anti-semitas", que "não quer saber o que acontece lá fora", mergulhando "com grande paixão em jogos de paciência e quebracabeças" (p. 174). Não é que a personagem Sidonie não visse o que acontecia lá fora. Ela simplesmente virava o rosto para o que via, mais preocupada com seu próprio bem-estar e, principalmente, em não se sentir humilhada. Em Viena, certa vez, se deparou com "gente como ela - judeus e judias", esfregando a rua, no frio, "com vestidos, ternos", com os dedos vermelhos e rachados. Mas "a humilhação de presenciar aquilo quase a fez fugir de horror a toda velocidade; ela teve que se controlar muito para seguir seu caminho tranqüila e discretamente" (p. 245). Em Cuba, também, ela sabia que "a elegância e a riqueza que via nas ruas durante o dia eram compradas quase sempre com o dinheiro dos negócios especulativos e da corrupção", sabia que "imperavam os grandes contrastes sociais e, sobretudo no campo, amarga miséria. Sessenta por cento dos bens estavam nas mãos dos americanos... Não obstante, na parte abastada da grande metrópole, o sabor do rum [era] bom..." Talvez devesse saber também dos inúmeros relatos sobre o enorme sofrimento que o regime de Franco estava causando na Espanha, porém isso não a impedia de "apreciar a estabilidade" desse regime.

A partir dessa leitura do livro, me pergunto se é esse o tipo de "testemunho" do século XX de que fala a orelha do livro. Um testemunho que desvia o olhar do sofrimento dos outros e segue seu caminho "tranqüila e discretamente"? Freud escreveu que Sidonie era uma "feminista", associando seu "feminismo" ao fato de ela considerar "injusto que as meninas não gozassem da mesma liberdade que os meninos, e se rebelar contra a sina das mulheres em geral" (1963, p. 156). Mas será que havia mesmo alguma rebeldia em Sidonie contra a sina e o sofrimento de quem quer que fosse?

Quaisquer que sejam as respostas a essas indagações, considero que a leitura do livro de Rieder e Voigt se presta a demonstrar bem o argumento de Foucault segundo o qual "a sexualidade é originária e historicamente burguesa 
e ... induz, em seus deslocamentos sucessivos e em suas transposições, efeitos de classe específicos" (1977, p. 120), e aí reside o valor principal do trabalho das autoras. 